\title{
Potassium bromate as positive assay control for the Fpg-modified comet assay
}

\author{
Peter Møller ${ }^{1, *, \infty}$, Damian Muruzabal ${ }^{2}$,Tamara Bakuradze ${ }^{3}$, Elke Richling ${ }^{3}$, \\ Ezgi Eyluel Bankoglu ${ }^{4}$, Helga Stopper ${ }^{4}$, Sabine A. S. Langie ${ }^{5,6, \bullet}$, \\ Amaya Azqueta ${ }^{2,7}$, Annie Jensen ${ }^{1}$, Francesca Scavone ${ }^{8}$, Lisa Giovannelli ${ }^{8}$, \\ Maria Wojewódzka ${ }^{9}$, Marcin Kruszewski ${ }^{9,10}$, Vanessa Valdiglesias ${ }^{11, \odot, ~}$ \\ Blanca Laffon ${ }^{12,}$, , Carla Costa ${ }^{13,14}$, Solange Costa ${ }^{13,14}$, \\ João Paulo Teixeira ${ }^{13,14}$, Mirko Marino ${ }^{15, \bullet}$, Cristian Del Bo' ${ }^{15}$, Patrizia Riso ${ }^{15}$, \\ Sergey Shaposhnikov ${ }^{16,17}$ and Andrew Collins ${ }^{16,17}$
}

\begin{abstract}
'Department of Public Health, Section of Environmental Health, University of Copenhagen, Øster Farimagsgade 5A, DK-1014 Copenhagen K, Denmark, ${ }^{2}$ Department of Pharmacology and Toxicology, University of Navarra, C/Irunlarrea 1, 31009 Pamplona, Spain, ${ }^{3}$ Food Chemistry \& Toxicology, Department of Chemistry, Technische Universitaet Kaiserslautern, Erwin-Schroedinger-Str. 52, D-67663 Kaiserslautern, Germany, ${ }^{4}$ Institute of Pharmacology and Toxicology, University of Würzburg, Versbacher Str. 9, 97078 Würzburg, Germany, ${ }^{5}$ VITO-Health, Boerentang 200, $2400 \mathrm{Mol}$, Belgium, ${ }^{6}$ Centre for Environmental Sciences, Hasselt University, Agoralaan Gebouw D, 3590 Diepenbeek, Belgium, 'IdiSNA, Navarra Institute for Health Research, C/Irunlarrea 3, 31008 Pamplona, Spain, ${ }^{8}$ Department NEUROFARBA University of Florence (Section Pharmacology and Toxicology), Viale G. Pieraccini 6, 50134 Florence, Italy, ${ }^{9}$ Center for Radiobiology and Biological Dosimetry Institute of Nuclear Chemistry and Technology, Dorodna 16, 03-195 Warszawa, Poland, ${ }^{10}$ Department of Medical Biology and Translational Research, Institute of Rural Health, Jaczewskiego 2, 20-090 Lublin, Poland, "Universidade da Coruña, Grupo DICOMOSA, Centro de Investigaciones Científicas Avanzadas (CICA), Departamento de Biología, Facultad de Ciencias, Campus A Zapateira s/n, 15071, A Coruña, Spain, ${ }^{12}$ Universidade da Coruña, Grupo DICOMOSA, Centro de Investigaciones Científicas Avanzadas (CICA), Departamento de Psicología, Facultad de Ciencias de la Educación, Campus Elviña s/n, 15071, A Coruña, Spain, ${ }^{13}$ Environmental Health Department, Instituto Nacional de Saúde Doutor Ricardo Jorge, Rua Alexandre Herculano 321, 4000-055 Porto, Portugal, ${ }^{14}$ EPIUnit - Instituto de Saúde Pública, Universidade do Porto, Rua das Taipas, $n^{0} 135,4050-600$ Porto, Portugal, ${ }^{15}$ Università degli Studi di Milano, Department of Food, Environmental and Nutritional Sciences (DeFENS), Via Giovanni Celoria 2, 20133 Milan, Italy, ${ }^{16}$ Department of Nutrition, University of Oslo, Sognsvannsveien 9, 0372, Oslo, Norway and ${ }^{17}$ NorGenotech AS, Norway
\end{abstract}

*To whom correspondence should be addressed. Tel: +45 35327654; Email: pemo@sund.ku.dk

Received 22 January 2020; Editorial decision 24 March 2020; Accepted 27 March 2020.

\begin{abstract}
The comet assay is a popular assay in biomonitoring studies. DNA strand breaks (or unspecific DNA lesions) are measured using the standard comet assay. Oxidative stress-generated DNA lesions can be measured by employing DNA repair enzymes to recognise oxidatively damaged DNA. Unfortunately, there has been a tendency to fail to report results from assay controls (or maybe even not to employ assay controls). We believe this might have been due to uncertainty as to what really constitutes a positive control. It should go without saying that a biomonitoring study cannot have a positive control group as it is unethical to expose healthy humans to DNA damaging (and thus potentially carcinogenic) agents. However, it is possible to include assay controls in the analysis (here meant as a cryopreserved sample of cells i.e. included in each experiment as a
\end{abstract}


reference sample). In the present report we tested potassium bromate $\left(\mathrm{KBrO}_{3}\right)$ as a positive comet assay control for the formamidopyrimidine DNA glycosylase (Fpg)-modified comet assay. Ten laboratories used the same procedure for treatment of monocytic THP-1 cells with $\mathrm{KBrO}_{3}(0.5,1.5$ and $4.5 \mathrm{mM}$ for $1 \mathrm{~h}$ at $37^{\circ} \mathrm{C}$ ) and subsequent cryopreservation. Results from one laboratory were excluded in the statistical analysis because of technical issues in the Fpg-modified comet assay. All other laboratories found a concentration-response relationship in cryopreserved samples (regression coefficients from 0.80 to 0.98 ), although with different slopes ranging from 1.25 to 11.9 Fpg-sensitive sites (\%DNA in tail) per $1 \mathrm{mM} \mathrm{KBrO}_{3}$. Our results demonstrate that $\mathrm{KBrO}_{3}$ is a suitable positive comet assay control.

\section{Introduction}

For approximately 30 years, the comet assay has been used in genetic toxicology and biomonitoring. The assay has been used in an overwhelming number of studies on environmental and occupational exposure, lifestyle factors, nutrition and diseases. It is considered to be a cheap, technically simple and fast assay that can be used for any cell type or tissue in animals, humans and plants. The standard alkaline comet assay measures DNA strand breaks. However, an additional step with enzymic treatment of DNA after the lysis step increases the types of lesions that the comet assay can detect. The most popular version of this enzyme-modified comet assay involves treatment with formamidopyrimidine DNA glycosylase (Fpg) for detection of 8-oxo-7,8-dihydroguanine$2^{\prime}$-deoxyguanosine and ring-opened purine lesions. Human 8-oxoguanine DNA glycosylase (hOGG1) can also be used to measure oxidatively damaged DNA. It has been suggested to be more specific for the detection of 8-oxodG (1).

A standard protocol for the comet assay should include procedures to assess inter-experimental variation and ascertain that the results are reliable (e.g. by using positive controls). However, this is not common practice, as demonstrated in a recent review on casecontrol studies where only 8 out of 98 articles mentioned the use of assay controls for DNA strand breaks and none was specific for oxidatively damaged DNA (2). An earlier review of 55 biomonitoring studies using the Fpg- or hOGG1-modified comet assay showed that only 5 studies had used hydrogen peroxide and 9 studies had used the photosensitiser Ro19-8022 (mainly articles coming from the same laboratory) (3). The evidence indicates that reporting results on assay controls is a rarity in articles on comet assay results. This may be due to negligence of just not reporting results on assay controls, but it may also be that researchers do not include such controls in their comet assay experiments. Members of the COST Action hCOMET have identified the lack of standard procedures for assay controls as a major issue that needs to be solved (4).

The standard alkaline comet assay is now adopted as an Organisation for Economic Co-operation and Development (OECD) guideline test for animal experiments and the guideline recommends the use of alkylating agents for positive controls (5). In addition, it should be emphasised that a positive control does not exist in biomonitoring studies since a group of people cannot be exposed deliberately to a DNA damaging agent. However, assay controls (or reference standards) are useful for quality control and assessment of inter-experiment variation. Cryopreserved cells that have been treated with the OECD-recommended alkylating agents would be good assay controls for the standard comet assay, whereas they are not appropriate for the enzyme-modified comet assay that detects oxidatively damaged DNA. Hydrogen peroxide is also not a particularly good assay control for the Fpg-modified comet assay because the concomitant generation of DNA strand breaks decreases the dynamic range of oxidatively damaged DNA. The photosensitiser
Ro19-8022, originally developed as a drug, failed the pre-clinical toxicity screening because it causes oxidative damage to DNA. Generously, F. Hoffmann La Roche distributed their stock of Ro198022 as a gift to researchers until the patent expired. The compound was instrumental in earlier ring trials that revealed a substantial variation in the detection of oxidatively damaged DNA between laboratories (6-8). Later ring trials also used Ro19-8022 and showed lower inter-laboratory variation in the measured levels of Fpg-sensitive sites when the results were standardised against assay control samples (911). As it stands today, Ro19-8022 is the only well-established assay control for the Fpg-modified comet assay, but it cannot be obtained from the major vendors (though Chiron AS sells it as a compound called 8503.23, www.chiron.no). Potassium bromate $\left(\mathrm{KBrO}_{3}\right)$ has similar desirable features as Ro19-8022 (i.e. high generation of Fpg-sensitive sites with little concurrent generation of DNA strand breaks) and it is readily available for all researchers.

The overarching purpose of this ring trial was to test $\mathrm{KBrO}_{3}$ as a positive assay control for the Fpg-modified comet assay. $\mathrm{KBrO}_{3}$ was chosen among several candidates as described previously (3). Preliminary tests indicated that $\mathrm{KBrO}_{3}$ might be a reliable positive assay control inasmuch as concentration-response relationships could be obtained in different laboratories. Ten laboratories prepared and tested cryopreserved assay control samples in three independent experiments. Slides from at least one experiment were forwarded to one central laboratory to assess the relative contribution of differences in scoring to the level of variation.

\section{Methods}

A full protocol for the cell culture condition, $\mathrm{KBrO}_{3}$ exposure and comet assay procedure is available in the supplement, available at Mutagenesis Online. The laboratories were instructed to analyse samples in the comet assay once a week for three consecutive weeks. Except for the coordinating laboratory, none of the laboratories had used $\mathrm{KBrO}_{3}$ as positive assay control in experiments prior to the work in the hCOMET Cost Action. Preliminary experiments were carried out by some of the participating laboratories to verify the suitability of the test conditions which had been used already in the coordinating laboratory (results not shown).

\section{Preparation of assay controls}

We used THP-1 cells as assay controls because all laboratories can purchase this cell line from American Type Culture Collection (ATCC), Manassas, VA, USA and it does not require a special cell culture facility (i.e. biosafety level 1). The cell line was originally developed from a 1-year-old boy with acute monocytic leukaemia. It is cultured as a single cell suspension. In the comet assay, undamaged THP-1 cells have very little DNA migration under normal electrophoresis conditions, and their nucleoids are typically completely round. In the present ring trial, all laboratories used THP-1 cells from the same batch. 
The THP- 1 cells were exposed to $0,0.5,1.5$ or $4.5 \mathrm{mM} \mathrm{KBrO}_{3}$ in Roswell Park Memorial Institute 1640 (RPMI-1640) medium for $1 \mathrm{~h}$ at $37^{\circ} \mathrm{C}$. Subsequently, the cells were washed and suspended in cryopreservation medium [50\% foetal bovine serum, 40\% RPMI1640 medium and 10\% dimethyl sulfoxide (DMSO)]. Each laboratory prepared at least 10 sets of vials for the ring-trial study (one set contains four vials: $0,0.5,1.5$ and $4.5 \mathrm{mM}$ ). Three vials were used for own analysis of DNA damage levels. The additional sets of samples were stored in order to be able to conduct further studies such as assessment of stability after long-term storage (i.e. analysis after years of cryopreservation, not yet done).

\section{Fpg enzyme}

Each laboratory received frozen vials with concentrated Fpg enzyme ( $5 \mu 1 ; 100$ times dilution from the original stock with a protein concentration of $9.6 \mu \mathrm{g} / \mu \mathrm{l}$ ) from the same laboratory (NorGenotech AS, Norway). The preparation method was essentially as was used for Fpg in the previous European Standards Committee on Oxidative DNA Damage (ESCODD) and European Comet Assay Validation Group (ECVAG) ring trials (6-11). The aliquots were further diluted 100 -fold $(500 \mu \mathrm{l})$ with Fpg reaction buffer $+10 \%$ glycerol and frozen at $-80^{\circ} \mathrm{C}$ until use in the comet assay (in $50 \mu \mathrm{l}$ vials). For use in an experiment, one aliquot $(50 \mu \mathrm{l})$ was diluted with $300 \mu \mathrm{l} \mathrm{Fpg}$ buffer and kept on ice until it was added to the gels. The final dilution was 60000 times with respect to the original stock.

\section{Reference control samples}

The reference control samples were prepared from human lymphoblastoid (TK6) cells treated with $1 \mathrm{mM}$ Ro19-8022 + visible light ( $33 \mathrm{~cm}$ from $500 \mathrm{~W}$ source, $5 \mathrm{~min}$ on ice). TK6 cells originate from a 5 -year boy with hereditary spherocytosis. The cell line is commercially available from ATCC. Each tube of reference control sample contained $0.5 \mathrm{ml}$ of cells in the freezing medium at a concentration of $0.5 \times 10^{6} / \mathrm{ml}$ (i.e. $0.25 \times 10^{6}$ cells per tube).

\section{Comet assay procedure}

A description of the specific steps in the protocol is available in the supplement, available at Mutagenesis Online. There was some flexibility in the protocol with respect to steps that are not considered important determinants for inter-laboratory variation. However, certain steps were fixed, including the final concentration of agarose $(0.7 \%)$, lysis time $(1 \mathrm{~h})$, alkaline unwinding time (20 $\mathrm{min})$, incubation time with Fpg $(1 \mathrm{~h})$ and electrophoresis conditions $\left(20 \mathrm{~V} / \mathrm{cm}^{*} \mathrm{~min}\right)$. Although standard incubation times are generally 30 or $45 \mathrm{~min}$, for this ring trial the incubation time with Fpg was set to $1 \mathrm{~h}$ to make sure the level of DNA incisions (or recognised DNA lesions) reached a plateau. Longer than $1 \mathrm{~h}$ incubation times with Fpg should be avoided because the baseline level of DNA damage may increase due to unspecific incisions. Electrophoresis depends on both the electrophoretic field strength (i.e. voltage per length unit in the electrophoresis tank) and duration of electrophoresis. It was not possible to standardise the type of dye because it depends on the filter in the fluorescence microscope. The types of dyes used were GelRed Nucleic Acid Gel Stain, ethidium bromide, 4',6-diamidino2-phenylindole, SYBR Gold and YOYO-1.

In the central laboratory, the slides were stained with SYBR Gold for $20 \mathrm{~min}$ (with slow shaking) and subsequently rinsed in distilled water. The original SYBR Gold solution was diluted 1:10 in DMSO and cryopreserved; on the day of use it was further diluted 1:1000 in Tris-EDTA buffer ( $1 \mathrm{mM}$ disodium ethylenediaminetetraacetate dihydrate and $10 \mathrm{mM}$ Tris- $\mathrm{HCl}$ adjusted to $\mathrm{pH}$ 8). Coverslips were added on top of the slide/film. Perceptive Instruments Comet Assay IV (Instem) was used for scoring the comets. The light source in the microscope was a fibre optic lamp and $\times 20$ magnification lens was used. Fifty comets per gel (100 comets per condition) were scored, except for slides from one laboratory that only sent samples with 1 gel per condition. The tail intensity (\%DNA in tail) parameter was used for the calculations.

\section{Statistical analysis}

Ten laboratories participated in the ring trial. All results per lab are reported in the supplement, available at Mutagenesis Online. Results from laboratory 10 have been excluded in the statistical analysis because of technical issues in the Fpg-modified comet assay: the samples of Ro19-8022-treated cells and Fpg were thawed upon arrival from the central lab due to unforeseen retention in the customs (see table of the results from laboratory 10 for further description of the experiments). The results from laboratory 10 are shown in the supplement, available at Mutagenesis Online in order to avoid reporting bias.

The results from each laboratory have been analysed by linear regression analysis or mixed effects models with categorical factor (i.e. laboratory) and $\mathrm{KBrO}_{3}$ concentration as predictors. The comparison of DNA damage levels obtained in individual laboratories and the central laboratory has been analysed with both true values and standardised values $\left[Z\right.$-score $=\left(X_{i}-\mu\right) /$ standard deviation, where $X_{i}$ is the value of the $i$ ' the data point and $\mu$ is the mean of all data points]. The statistical analysis was carried out in Stata/IC 13.1 (Stata Corp, College Station, TX, USA).

\section{Results}

The majority of the laboratories reported a $\mathrm{KBrO}_{3}$ concentrationdependent increase in Fpg-sensitive sites (Figure 1 and Table 1). The variation in levels of Fpg-sensitive sites was large, indicating inter-laboratory variation in the preparation or analysis of samples. Illustrating the variation, the laboratory with the smallest slope in the full concentration-response relationship had a range from 0.2 to 6.0 $\%$ DNA in tail ( lope $=1.25, r=0.98, P<0.001$ ) and the laboratory with the largest slope had 0.6 to $52.5 \%$ DNA in tail (slope $=11.9$ $r=0.95, P<0.001$ ). Both laboratories have almost perfect linear relationships. One laboratory had saturation of Fpg-sensitive sites at the highest concentration of $\mathrm{KBrO}_{3}$ (there was a lower level of Fpg-sensitive sites in samples treated with $4.5 . \mathrm{mM}$ than expected from linear extrapolation from $0.5-1.5$ to $4.5 \mathrm{mM}$ ). In contrast to Fpg-sensitive sites, levels of DNA strand breaks were not increased by $\mathrm{KBrO}_{3}$ exposure in any of the laboratories (Table 2).

Seven out of the eight laboratories, which analysed Ro19-8022 samples, reported that the level of Fpg-sensitive sites in the Ro198022 samples was between the level of DNA damage in samples that had been treated with 0.5 and $4.5 \mathrm{mM} \mathrm{KBrO}_{3}$. Likewise, nine laboratories reported that the level of DNA strand breaks in the Ro19-8022 samples was higher than the level in the $\mathrm{KBrO}_{3}$ samples (Table 2). The results indicate a high consistency in results from different laboratories, although the results also reveal a substantial degree of inter-laboratory variation in levels of both DNA strand breaks and Fpg-sensitive sites.

Slides from six laboratories were stained and scored in an independent central laboratory by the same investigator. Table 3 shows that the variation in DNA damage levels of $\mathrm{KBrO}_{3}$-treated THP-1 cells is lower when the samples are stained with the same dye and scored with the same image analysis software. Similarly, the inter-laboratory variation in Ro19-8022 samples was lower in slides that were stained 


\section{Laboratory 1}

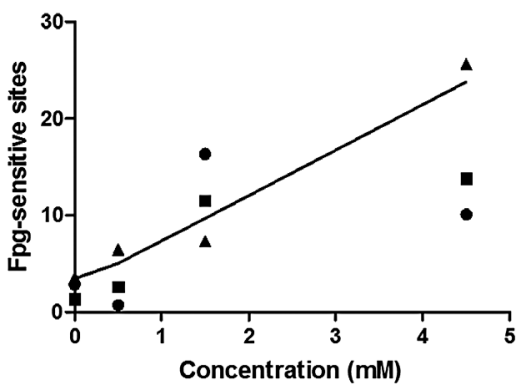

Laboratory 4

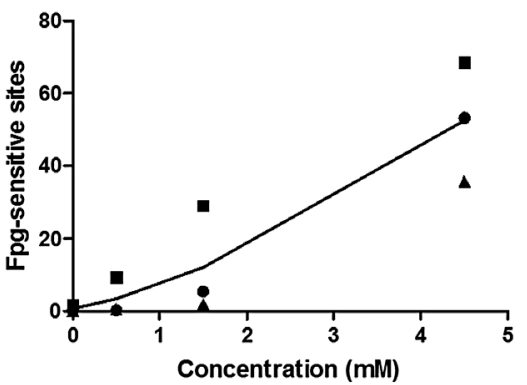

Laboratory 7

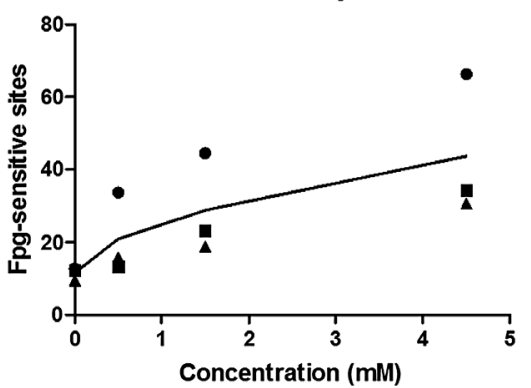

Laboratory 2

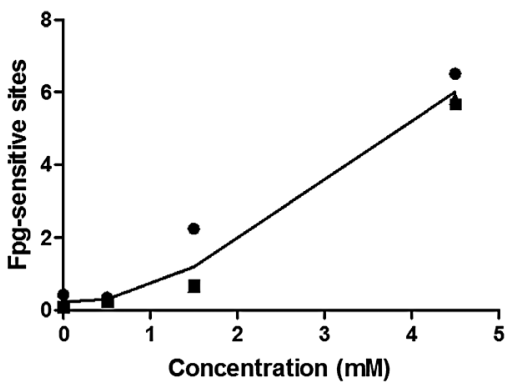

Laboratory 5

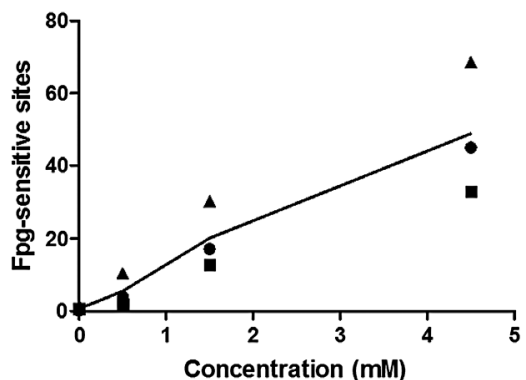

Laboratory 8

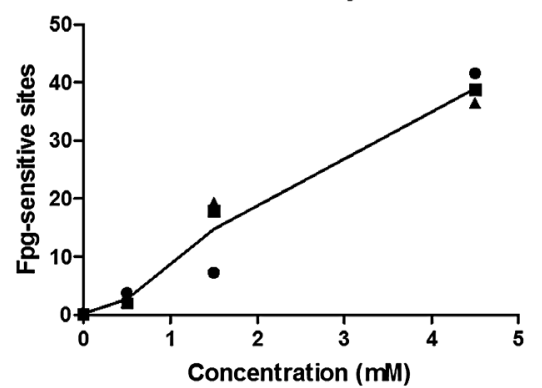

Laboratory 3

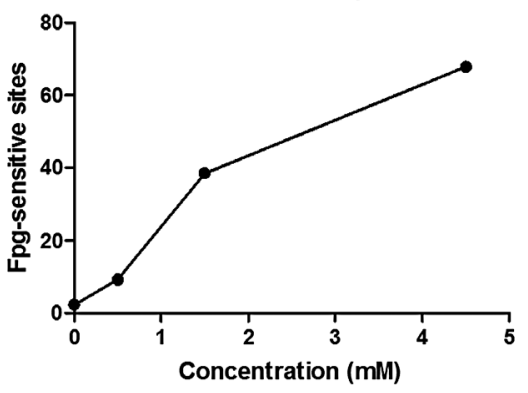

Laboratory 6

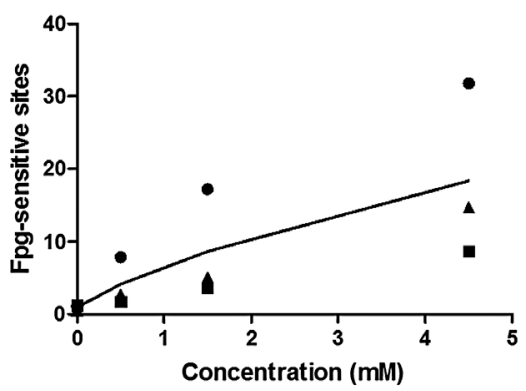

Laboratory 9

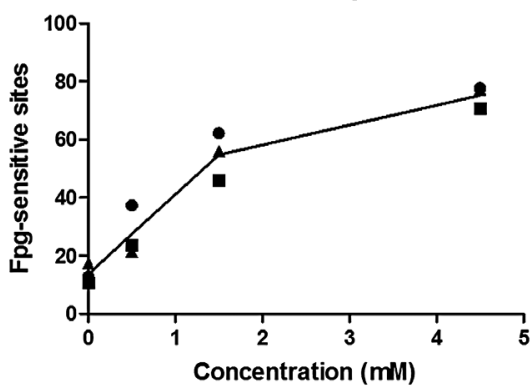

Figure 1. Levels of Fpg-sensitive sites in cryopreserved samples ofTHP-1 cells after exposure to $\mathrm{KBrO}_{3}$ in the different laboratories, for up to three experiments.

Table 1. Levels of Fpg-sensitive sites in cells exposed to $\mathrm{KBrO}_{3}$ or $\mathrm{Ro} 19-8022$

\begin{tabular}{|c|c|c|c|c|c|c|}
\hline \multirow[t]{2}{*}{ Lab ID } & \multicolumn{5}{|l|}{$\mathrm{KBrO}_{3}$} & \multirow[t]{2}{*}{ Ro19-8022 } \\
\hline & $0 \mathrm{mM}$ & $0.5 \mathrm{mM}$ & $1.5 \mathrm{mM}$ & $4.5 \mathrm{mM}$ & $r$-value & \\
\hline 1 & $2.6 \pm 1.1$ & $3.3 \pm 2.9$ & $11.7 \pm 4.5$ & $16.5 \pm 8.1$ & $0.80^{* * *}$ & $7.4 \pm 3.8$ \\
\hline 2 & $0.2 \pm 0.2$ & $0.3 \pm 0.1$ & $1.2 \pm 0.9$ & $6.0 \pm 0.4$ & $0.98 * * *$ & $4.7 \pm 0.7$ \\
\hline 3 & 2.3 & 9.2 & 38.5 & 67.8 & $0.97 *$ & ND \\
\hline 4 & $0.6 \pm 1.0$ & $3.4 \pm 5.1$ & $12.1 \pm 14.7$ & $52.5 \pm 16.4$ & $0.96^{* * *}$ & $32.9 \pm 3.9$ \\
\hline 5 & $0.7 \pm 0.8$ & $5.5 \pm 4.5$ & $20.1 \pm 9.1$ & $48.8 \pm 18.2$ & $0.96 * * *$ & $25.1 \pm 11.9$ \\
\hline 6 & $0.9 \pm 0.4$ & $4.1 \pm 3.3$ & $8.6 \pm 7.4$ & $18.4 \pm 12.0$ & $0.91 * *$ & $19.2 \pm 14.1$ \\
\hline 7 & $11.5 \pm 1.7$ & $20.9 \pm 11.1$ & $28.8 \pm 13.8$ & $43.7 \pm 19.6$ & $0.92 * *$ & $27.5 \pm 1.7$ \\
\hline 8 & $0.2 \pm 0.1$ & $2.7 \pm 0.9$ & $14.7 \pm 6.6$ & $38.9 \pm 2.6$ & $0.98 * * *$ & $17.1 \pm 1.3$ \\
\hline 9 & $13.6 \pm 3.5$ & $27.4 \pm 8.6$ & $54.7 \pm 8.2$ & $75.2 \pm 3.9$ & $0.93 * * *$ & $47.2 \pm 2.9$ \\
\hline
\end{tabular}

Results are mean and \pm standard deviation from three independent experiments. Laboratory 3 had assay problems (a recurrent technical problem that results in high baseline levels of DNA strand breaks at the same time of the year). In addition, there was problems with the delivery of Ro19-8022 [thus, DNA damage is not determined (ND) in this sample in laboratory 3]. Laboratory 5 used visual scoring (0-100 arbitrary unit scale). Linear regression ( $r$-values).

$$
\begin{aligned}
& * P<0.05 . \\
& * P<<0.01 . \\
& * * * P<0.001 .
\end{aligned}
$$

and scored in the central laboratory as compared with the values obtained in individual laboratories (Table 4). The Fpg-sensitive sites in the Ro19-8022 samples ranged from 4.7 to $47.2 \%$ DNA in tail
$(\mathrm{CoV}=59 \%)$. This was reduced to $28 \%$ in slides that were scored in the central laboratory (range from 7.2 to $16.3 \% \mathrm{DNA}$ in tail). Figure 2 shows a comparison of the level of Fpg-sensitive sites that 
Table 2. Levels of DNA strand breaks in cells exposed to $\mathrm{KBrO}_{3}$ or Ro19-8022

\begin{tabular}{|c|c|c|c|c|c|}
\hline \multirow[t]{2}{*}{ Lab ID } & \multicolumn{4}{|l|}{$\mathrm{KBrO}_{3}$} & \multirow[t]{2}{*}{ Ro19-8022 } \\
\hline & $0 \mathrm{mM}$ & $0.5 \mathrm{mM}$ & $1.5 \mathrm{mM}$ & $4.5 \mathrm{mM}$ & \\
\hline 1 & $15.3 \pm 3.0$ & $9.3 \pm 3.1$ & $16.5 \pm 4.9$ & $10.0 \pm 3.7$ & $31.7 \pm 11.0$ \\
\hline 2 & $0.6 \pm 0.1$ & $1.1 \pm 0.6$ & $1.3 \pm 0.5$ & $1.1 \pm 0.3$ & $4.0 \pm 0.2$ \\
\hline 3 & 0.9 & 1.0 & 1.0 & 0.9 & ND \\
\hline 4 & $0.7 \pm 0.3$ & $1.0 \pm 1.3$ & $0.8 \pm 0.5$ & $1.3 \pm 1.1$ & $6.3 \pm 3.1$ \\
\hline 5 & $2.9 \pm 1.5$ & $2.9 \pm 3.0$ & $2.9 \pm 2.8$ & $2.6 \pm 2.1$ & $20.0 \pm 8.1$ \\
\hline 6 & $4.6 \pm 1.0$ & $4.1 \pm 3.0$ & $3.7 \pm 1.8$ & $4.3 \pm 04$ & $10.4 \pm 0.2$ \\
\hline 7 & $6.1 \pm 3.3$ & $5.2 \pm 2.2$ & $4.7 \pm 1.5$ & $6.2 \pm 2.2$ & $34.5 \pm 12.9$ \\
\hline 8 & $2.6 \pm 0.9$ & $2.7 \pm 0.8$ & $3.5 \pm 1.7$ & $4.0 \pm 3.0$ & $12.0 \pm 5.1$ \\
\hline 9 & $3.2 \pm 1.8$ & $2.8 \pm 1.3$ & $3.4 \pm 1.7$ & $3.5 \pm 1.6$ & $11.9 \pm 4.7$ \\
\hline
\end{tabular}

Results are mean and \pm standard deviation from three independent experiments. There were no concentration-response relationships in any of the laboratories. Laboratory 3 had assay problems (a recurrent technical problem that results in high baseline levels of DNA strand breaks at the same time of the year). In addition, there was problems with the delivery of Ro19-8022 [thus, DNA damage is not determined (ND) in this sample in laboratory 3]. Laboratory 5 used visual scoring (0-100 arbitrary unit scale).

Table 3. Comparison of inter-laboratory variation (i.e. coefficient of variation of \%DNA in tail) in Fpg-sensitive sites in THP-1 cells treated with $\mathrm{KBrO}_{3}$

\begin{tabular}{lcc}
\hline Sample & Original results $^{\mathrm{a}}$ & Standardised results $^{\mathrm{b}}$ \\
\hline $0 \mathrm{mM}$ & 157 & 122 \\
$0.5 \mathrm{mM}$ & 124 & 80 \\
$1.5 \mathrm{mM}$ & 95 & 58 \\
$4.5 \mathrm{mM}$ & 70 & 50 \\
\hline
\end{tabular}

aResults from laboratories 1, 2, 4, 6 and 8 , which were also analysed in the central laboratory.

bStandardised according to the level of Fpg-sensitive sites in the Ro198022 sample from the individual laboratory.

Table 4. Comparison of inter-laboratory variation (i.e. coefficient of variation of \%DNA in tail) in DNA damage levels in cryopreserved samples of TK6 cells treated with Ro19-8022

\begin{tabular}{llll}
\hline Types of DNA damage & All $^{\mathrm{a}}$ & Own analysis $^{\mathrm{b}}$ & Central laboratory $^{\mathrm{b}}$ \\
\hline $\begin{array}{l}\text { DNA strand breaks } \\
\text { (Ro19-8022) }\end{array}$ & 67 & 93 & 32 \\
$\begin{array}{l}\text { Fpg-sensitive sites } \\
\text { (Ro19-8022) }\end{array}$ & 61 & 59 & 28 \\
\hline
\end{tabular}

${ }^{a}$ Results from laboratories 1, 2 and 4-9.

${ }^{\mathrm{b}}$ Results from laboratories 1, 2, 4, 6 and 8 .

were measured by the individual laboratories and slides from the same experiments in the central laboratory. There is no significant correlation between the concentration-response relationship of samples in the central and individual laboratories $(r=0.74, P=0.09, n=6)$. A different analysis, using either DNA damage levels (\%DNA in tail or visual score) or standardised values ( $Z$-score) indicates a positive association between DNA damage levels in the central laboratory and individual laboratories $(r=0.71, P<0.001$ and $r=0.69, P<0.01$, linear mixed effect model with type of DNA damage as categorical factor; Figure 2 middle and bottom panels, respectively).

\section{Discussion}

Unfortunately, it has been uncommon to report values of positive assay controls for the enzyme-modified comet assay using either
Fpg or hOGG1. A positive assay control is defined as a cryopreserved sample i.e. included in every comet assay run. It serves both as a quality control for the activity of the Fpg (or hOGG1) enzyme and as a way to assess experimental variation over time. There is no consensus about suitable positive assay controls for the enzymemodified comet assay. Researchers should not be discouraged from using other chemicals than $\mathrm{KBrO}_{3}$, but attention should be paid to the increasing awareness that reports on comet assay results are deemed unreliable if assay controls are not reported. This goes also for biomonitoring studies using only the standard comet assay (without enzymes), where assay controls should be included for the quality control of the detection of DNA strand breaks. The OECDrecommended positive controls are good candidates as positive assay controls for DNA strand breaks in biomonitoring studies. However, the majority of the OECD-recommended positive controls are classified as carcinogens by the International Agency for Research on Cancer (IARC) and it might be preferable to use a non-classified compound, such as hydrogen peroxide, for safety reasons. In general, either fresh or cryopreserved samples from a biomonitoring trial can be analysed in the comet assay with similar results, and there are advantages and disadvantages to either way of analysis. In cases where there are large numbers of fresh or cryopreserved samples demanding analysis, it might not be possible to score the slides until several electrophoresis runs have occurred. However, it is recommended to score the control samples as they are produced to check for a drift in the assay conditions.

It was reported already 20 years ago that $\mathrm{KBrO}_{3}$ produces Fpgsensitive sites in Chinese hamster lung cells (12). Later studies have used myeloid mononuclear cells such as L5178Y (1,13), THP-1 (14), TK6 (15), peripheral blood mononuclear cells and isolated T-lymphocytes (16). It has also been shown that $\mathrm{KBrO}_{3}$ induces hOGG1-sensitive sites $(1,13,14)$. It should be noted that earlier studies assessed levels of Fpg-sensitive sites in fresh cells. The use of cryopreserved $\mathrm{KBrO}_{3}^{-}$ exposed THP-1 cells as assay controls or as substrate cells for the in vitro comet repair assay has been standard practice in one laboratory (17-21). Interestingly, $\mathrm{KBrO}_{3}$ has been used as a positive control in a study on rats where oral administration generated hOGG1-sensitive sites in both the liver and kidney, without concurrent generation of DNA strand breaks (22). $\mathrm{KBrO}_{3}$ causes kidney tumours after oral exposure in the drinking water in different animal species (23).

The results from this ring trial show that $\mathrm{KBrO}_{3}$ suitable for producing assay controls, using THP- 1 cells. $\mathrm{KBrO}_{3}$ is genotoxic via a mechanism whereby glutathione activates bromate to 

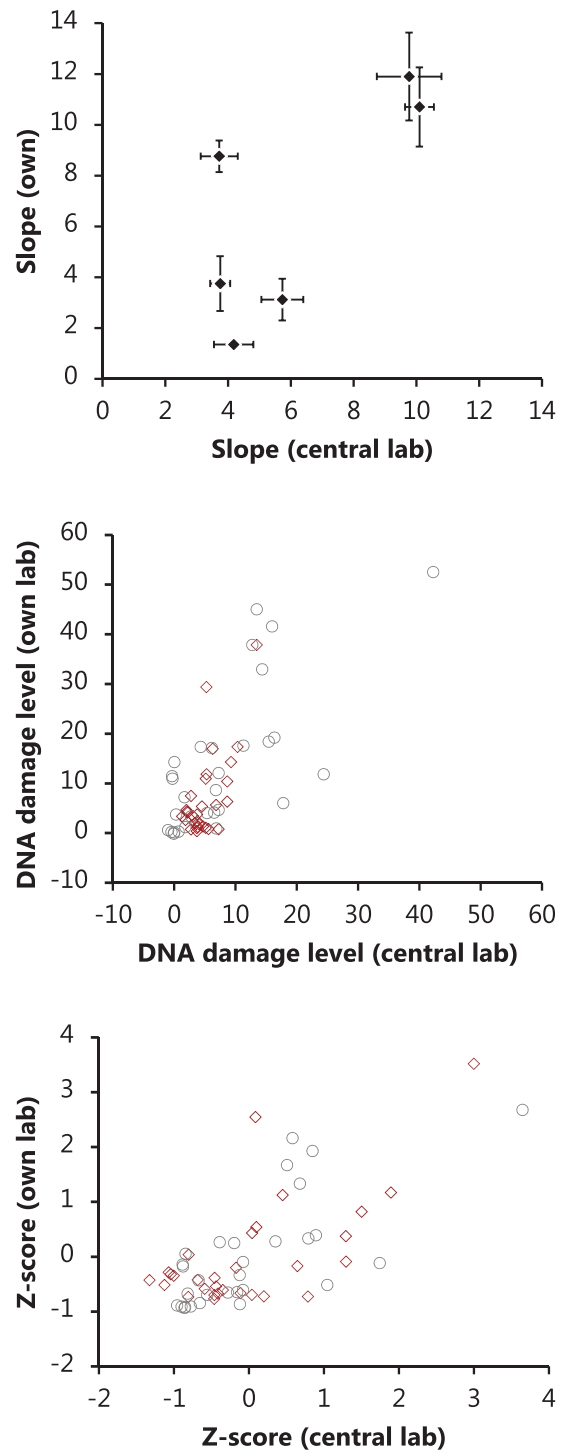

Figure 2. Comparison of concentration response relationships between comet assay slides scored in own laboratories $(n=6)$ and a central laboratory. The top panel shows the slopes of $\mathrm{KBrO}_{3}$ concentration response curves (mean slope and standard error). The middle and bottom panels depict the DNA damage level (\%DNA in tail or visual score) or standardised values (i.e. Z-score) of individual data points of $\mathrm{KBrO}_{3}$ and reference samples. The symbols are DNA strand breaks (diamonds) and Fpg-sensitive sites (circles). A linear effect model (with type of DNA damage as categorical factor) indicates a positive association for both DNA damage levels ( $r$-value $=0.71$, $P<0.001$, middle panel) $Z$-scores ( $r$-value $=0.69, P<0.01$, bottom panel).

bromine radicals or oxides, which causes oxidation of guanines in DNA (24). Most cells contain 1-2 mM glutathione, while certain highly metabolically active cells such as hepatocytes contain up to $10 \mathrm{mM}(25)$. It is likely that $\mathrm{KBrO}_{3}$ causes damage to DNA in most, if not all, standard cell lines and primary cells, but there might be differences in sensitivity to DNA damage. In addition, it has been shown that extending the alkaline unwinding time from 20 to 60 min increased the level of DNA strand breaks in $\mathrm{KBrO}_{3}$ treated cells (13). This suggests that the alkaline unwinding time should be kept as short as possible in order to avoid generation of DNA strand breaks, which will reduce the dynamic range of the Fpg-sensitive sites.
In our study, certain laboratories reported an unexpected attachment of unexposed THP-1 cells to the plastic flasks. This was not related to the $\mathrm{KBrO}_{3}$ treatment. We suspect it was due to activation of THP-1 cells to macrophage-like cells. It is relatively easy to transform THP-1 cells by stimulation with phorbol-12-myristate13-acetate, which is used in e.g. particle toxicology to obtain cells that actively engulf particles. We suspect that chemical constituents of plastic containers in certain laboratories may promote activation by delivering a suitable layer for attachment. In the affected laboratories, the problem was obviated by only using cells in suspension.

Results from one laboratory showed a saturation of Fpg-sensitive sites at the highest concentration of $\mathrm{KBrO}_{3}$ in the current comet assay settings. We used fixed comet assay procedures for steps that are considered to be most important determinants for inter-laboratory variation. Slightly modified comet assay procedures would bring the DNA damage levels below the dynamic range of the comet assay conditions or it would be necessary to use a lower maximal $\mathrm{KBrO}_{3}$ concentration. In any case, investigators are recommended to use the $\mathrm{KBrO}_{3}$ concentration span that best fits their comet assay conditions. If only one comet assay control sample is used, it is recommended to use a concentration in the linear part of the concentration-response curve to avoid saturation of the Fpg-sensitive sites. It is advisable to have equal variation below and above the mean value. For example, a positive assay control with a mean value of $100 \% \mathrm{DNA}$ in tail would have a skewed distribution as DNA damage levels cannot be above $100 \%$. In that case, the assay control would not reflect the variation in the assay and it would not be useful for standardisation of results in case there was inter-experimental variation in the analysis.

The participating laboratories were asked to forward extra slides from at least one experiment to a central laboratory to test the variation in reported DNA damage levels using the same dye and image analysis system. As the Ro19-8022 samples came from the same batch of cells, they should have the same level of \%DNA in tail and can thus be used to gain insight into sources of inter-laboratory variation in reported DNA damage levels. The CoV for Fpg-sensitive sites in Ro19-8022-treated cells (59\%) reflects all sources of variation for the inter-laboratory variation in the Fpg-modified comet assay. The analysis of slides in the central laboratory shows some inter-laboratory variation in levels of Fpg-sensitive sites in Ro198022 reference samples $(\mathrm{CoV}=28 \%)$, which is attributed to differences in procedures other than the type of dye and image analysis system. Thus, it appears that for reference samples the overall interlaboratory variation can be separated into somewhat equal contributions from handling (steps from slide preparation to drying before staining) and scoring (type of dye, microscope and image analysis system).

Standardisation of the $\mathrm{KBrO}_{3}$ data against the reference control decreases the inter-laboratory variation, although this is not completely removed. Similar reduction of the variation by standardisation has been seen in other comet assay validation trials within the same laboratory (26-29) and between laboratories (9-11). We hypothesise that this residual inter-laboratory variation after standardisation is mainly due to differences in cell culture and manipulation procedures among laboratories, and only to a smaller extent to differences in the comet assay procedure.

Overall, our results indicate that cells treated with $\mathrm{KBrO}_{3}$ can be used as a true positive control for the Fpg-modified comet assay in THP-1 and possibly other mammalian cell cultures. To the best of our knowledge, THP-1 cells are not recommended in OECD guidelines on other genotoxicity tests. However, it should be emphasised 
that cell lines described in OECD guideline documents might have been selected for special reasons. For instance, TK-6 cells are heterozygous for thymidine kinase and therefore desirable to be used in mutation assays. We decided against TK-6 as the cell line of choice for the testing of $\mathrm{KBrO}_{3}$ as a positive control because ATCC describes it as a biosafety level 2 type of organism, indicating moderate potential hazard to personnel and the environment. We also decided against freshly isolated human mononuclear blood cells because it may introduce 'batch variation' due to intra-individual and interindividual differences in the level of Fpg-sensitive sites.

In conclusion, the present study demonstrates a consistency in the $\mathrm{KBrO}_{3}$ concentration-response relationship in samples prepared in different laboratories, indicating that cells treated with $\mathrm{KBrO}_{3}$ provide a robust assay control.

\section{Supplementary data}

Supplementary data are available at Mutagenesis Online.

\section{Acknowledgement}

The authors thank the hCOMET project (COST Action, CA15132) for support. Carla Costa and Solange Costa were supported by grants FCT-SFRH/ BPD/96196/2013 and SFRH/BPD/100948/2014, respectively.

Conflict of interest statement: None declared.

\section{References}

1. Smith, C. C., O'Donovan, M. R. and Martin, E. A. (2006) hOGG1 recognizes oxidative damage using the comet assay with greater specificity than FPG or ENDOIII. Mutagenesis, 21, 185-190.

2. Møller, P., Stopper, H. and Collins, A. R. (2020) Measurement of DNA damage with the comet assay in high-prevalence diseases: current status and future directions. Mutagenesis, 35, 5-18.

3. Møller, P., Jantzen, K., Løhr, M., Andersen, M. H., Jensen, D. M., Roursgaard, M., Danielsen, P. H., Jensen, A. and Loft, S. (2018) Searching for assay controls for the Fpg- and hOGG1-modified comet assay. Mutagenesis, 33, 9-19.

4. Azqueta, A., Muruzabal, D., Boutet-Robinet, E., Milic, M., Dusinska, M., Brunborg, G., Møller, P. and Collins, A. R. (2019) Technical recommendations to perform the alkaline standard and enzyme-modified comet assay in human biomonitoring studies. Mutat. Res., 843, 24-32.

5. OECD (2016), Test No. 489: In Vivo Mammalian Alkaline Comet Assay, OECD Guidelines for the Testing of Chemicals, Section 4, OECD Publishing, Paris, https://doi.org/10.1787/9789264264885-en.

6. ESCODD (European Standards Committee on Oxidative DNA Damage). (2002) Comparative analysis of baseline 8-oxo-7,8-dihydroguanine in mammalian cell DNA, by different methods in different laboratories: an approach to consensus. Carcinogenesis, 23, 2129-2133.

7. ESCODD (European Standards Committee on Oxidative DNA Damage), Gedik, C. M. and Collins, A. (2005) Establishing the background level of base oxidation in human lymphocyte DNA: results of an inter-laboratory validation study. FASEB J., 19, 82-84.

8. ESCODD (European Standards Committee on Oxidative DNA Damage). (2003) Measurement of DNA oxidation in human cells by chromatographic and enzymic methods. Free Radic. Biol. Med., 34, 1089-1099.

9. Johansson, C., Møller, P., Forchhammer, L., et al. (2010) An ECVAG trial on assessment of oxidative damage to DNA measured by the comet assay. Mutagenesis, 25, 125-132.

10. Ersson, C., Møller, P., Forchhammer, L., et al. (2013) An ECVAG interlaboratory validation study of the comet assay: inter- and intra-laboratory variation of DNA strand breaks and FPG-sensitive sites in human mononuclear cells. Mutagenesis, 28, 279-286.
11. Godschalk, R. W., Ersson, C., Stepnik, M., et al. (2014) Variation of DNA damage levels in peripheral blood mononuclear cells isolated in different laboratories. Mutagenesis, 29, 241-249.

12. Speit, G., Haupter, S., Schütz, P. and Kreis, P. (1999) Comparative evaluation of the genotoxic properties of potassium bromate and potassium superoxide in V79 Chinese hamster cells. Mutat. Res., 439, 213-221.

13. Priestley, C. C., Green, R. M., Fellows, M. D., Doherty, A. T., Hodges, N. J. and O'Donovan, M. R. (2010) Anomalous genotoxic responses induced in mouse lymphoma L5178Y cells by potassium bromate. Toxicology, 267, $45-53$.

14. Møller, P., Jensen, D. M., Christophersen, D. V., et al. (2015) Measurement of oxidative damage to DNA in nanomaterial exposed cells and animals. Environ. Mol. Mutagen., 56, 97-110.

15. Platel, A., Nesslany, F., Gervais, V., Claude, N. and Marzin, D. (2011) Study of oxidative DNA damage in TK6 human lymphoblastoid cells by use of the thymidine kinase gene-mutation assay and the in vitro modified comet assay: determination of No-Observed-Genotoxic-Effect-Levels. Mutat. Res., 726, 151-159.

16. Bausinger, J. and Speit, G. (2014) Induction and repair of DNA damage measured by the comet assay in human $\mathrm{T}$ lymphocytes separated by immunomagnetic cell sorting. Mutat. Res., 769, 42-48.

17. Løhr, M., Jensen, A., Eriksen, L., Grønbæk, M., Loft, S. and Møller, P. (2015) Association between age and repair of oxidatively damaged DNA in human peripheral blood mononuclear cells. Mutagenesis, 30, 695-700.

18. Skovmand, A., Damiao Gouveia, A. C., Koponen, I. K., Møller, P., Loft, S. and Roursgaard, M. (2017) Lung inflammation and genotoxicity in mice lungs after pulmonary exposure to candle light combustion particles. Toxicol. Lett., 276, 31-38.

19. Andersen, M. H. G., Saber, A. T., Clausen, P. A., et al. (2018) Association between polycyclic aromatic hydrocarbon exposure and peripheral blood mononuclear cell DNA damage in human volunteers during fire extinction exercises. Mutagenesis, 33, 105-115.

20. Andersen, M. H. G., Frederiksen, M., Saber, A. T., et al. (2019) Health effects of exposure to diesel exhaust in diesel-powered trains. Part. Fibre Toxicol., 16, 21.

21. Jensen, D. M., Løhr, M., Sheykhzade, M., Lykkesfeldt, J., Wils, R. S., Loft, S. and Møller, P. (2019) Telomere length and genotoxicity in the lung of rats following intragastric exposure to food-grade titanium dioxide and vegetable carbon particles. Mutagenesis, 34, 203-214.

22. Pfuhler, S., Downs, T. R., Allemang, A. J., Shan, Y. and Crosby, M. E. (2017) Weak silica nanomaterial-induced genotoxicity can be explained by indirect DNA damage as shown by the OGG1-modified comet assay and genomic analysis. Mutagenesis, 32, 5-12.

23. IARC Monographs on the evaluation of carcinogenic risk to humans. (1999) Some Chemicals That Cause Tumours of the Kidney or Urinary Bladder in Rodents and Other Substances. IARC, Lyon, France.

24. Ballmaier, D. and Epe, B. (2006) DNA damage by bromate: mechanism and consequences. Toxicology, 221, 166-171.

25. Forman, H. J., Zhang, H. and Rinna, A. (2009) Glutathione: overview of its protective roles, measurement, and biosynthesis. Mol. Aspects Med., 30, $1-12$.

26. Møller, P., Friis, G., Christensen, P. H., et al. (2004) Intra-laboratory comet assay sample scoring exercise for determination of formamidopyrimidine DNA glycosylase sites in human mononuclear blood cell DNA. Free Radic. Res., 38, 1207-1214.

27. Forchhammer, L., Bräuner, E. V., Folkmann, J. K., Danielsen, P. H., Nielsen, C., Jensen, A., Loft, S., Friis, G. and Møller, P. (2008) Variation in assessment of oxidatively damaged DNA in mononuclear blood cells by the comet assay with visual scoring. Mutagenesis, 23, 223-231.

28. Forchhammer, L., Johansson, C., Loft, S., et al. (2010) Variation in the measurement of DNA damage by comet assay measured by the ECVAG inter-laboratory validation trial. Mutagenesis, 25, 113-123.

29. Forchhammer, L., Ersson, C., Loft, S., et al. (2012) Inter-laboratory variation in DNA damage using a standard comet assay protocol. Mutagenesis, 27, 665-672. 
